\title{
Análise de Impacto Regulatório: uma ferramenta e um procedimento para a melhoria da regulação
}

\author{
Regulatory Impact Analysis: a tool and procedure for improving regulation
}

\author{
Luiz Alberto Blanchet* \\ Priscila Lais Ton Bubniak*
}

\section{Resumo}

\begin{abstract}
A Análise de Impacto Regulatório (AIR) é importante não só como ferramenta apta a avaliar os custos, benefícios e efeitos da regulação, mas como procedimento administrativo que, com a participação dos envolvidos no processo regulatório, pode auxiliar na tomada de decisões regulatórias, limitando a discricionariedade do regulador. A Reforma Gerencial e a consequente configuração de um Estado Regulador são noções pertinentes para a compreensão da importância da AIR, destacando-se a relevância da regulação não só para a correção das falhas de mercado, mas para a persecução dos objetivos estabelecidos na Constituição. No estudo sobre a AIR, abordar-se-ão conceitos, métodos, classificações, possíveis resultados, práticas já adotadas por agências reguladoras brasileiras e correspondente legislação, bem como aspectos do Projeto de Lei no 1.539/2015, que pretende tornar obrigatória a adoção da AIR pelas Agências Reguladoras federais.
\end{abstract}

Palavras-chave: Regulação. Eficiência. Desenvolvimento. Análise de impacto regulatório. Discricionariedade.

\section{Abstract}

Regulatory Impact Analysis (RIA) is important not only as a tool to assess the costs, benefits, and effects of regulation but as an administrative procedure that may assist in the making of regulatory decisions limiting the discretion of the regulator having the participation of those involved in the regulatory process. Management Reform and the consequent configuration of a Regulatory State are pertinent notions for understanding the importance of AIR. It highlights the relevance of regulation not only for the correction of market failures but for the pursuit of the objectives established in the Constitution. In the study on RIA, RIA, concepts, methods, classifications, possible outcomes, practices will be addressed and are already adopted by Brazilian regulatory agencies and corresponding legislation, as well as aspects of Bill n. 1.539 / 2015, which intends to make AIR through the Federal Regulatory Agencies.

Keywords: Regulation. Efficiency. Development. Regulatory impact analysis. Discretion.

\section{Introdução}

A forma de intervenção dos Estados na economia, de modo a promover o bem-estar social e econômico dos cidadãos, está intimamente vinculada à dinâmica das relações entre Estado e sociedade, decorrente de circunstâncias ideológicas, políticas, sociais e econômicas, e sua consequente influência nas instituições jurídicas.

A opção preferencial do Estado pela intervenção indireta, normativa, adveio da Reforma Gerencial, promovida na década de 90, que substituiu o paradigma do Estado atuante na exploração da atividade econômica por um Estado regulador. Ademais, inserida em um contexto de reformas regulatórias mundiais,

Doutor e Mestre em Direito pela Universidade Federal do Paraná. Professor do Programa de Pós-graduação da Pontifícia Universidade Católica do Paraná. Advogado. Curitiba-PR - Brasil. E-mail: blanchet@blanchet.adv.br.

Mestra em Direito Econômico e Desenvolvimento pelo Programa de Pós-graduação em Direito da Pontifícia Universidade Católica do Paraná. Bacharel em Direito pela Pontifícia Universidade Católica do Paraná. Advogada. Curitiba-PR - Brasil. E-mail: priscila@sanchezrios.com.br. 
elaboradas a partir das recomendações para membros e não membros do Comitê de Política Regulatória da Organização para a Cooperação e Desenvolvimento Econômico (OCDE), buscou substituir o modelo burocrático, preocupado com os processos, pelo modelo gerencial, voltado para a obtenção de resultados (eficiência) e para a qualidade da administração pública.

Assim, norteado não só pela crescente preocupação com a qualidade da intervenção do Estado em questões econômicas, sociais e ambientais, mas também pela necessidade de aperfeiçoamento da participação dos interessados no processo regulatório, a fim de lhe conferir legitimidade, o presente trabalho parte de uma análise constitucional sobre a ordem econômica e o papel do Estado como agente regulador. Sob essa perspectiva, há que se compreender o Estado como agente ativo, voltado à perseguição dos fins e objetivos enunciados, superando uma tradicional postura destinada a corrigir as denominadas falhas de mercado.

Dessa forma, após uma exposição sobre a importância, os conceitos e os métodos utilizados na Análise de Impacto Regulatório (AIR), bem como a abordagem das práticas já adotadas pelas agências reguladoras brasileiras e sua positivação, tece-se, em paralelo, alguns comentários sobre o Projeto de Lei $n^{\circ} 1.539 / 2015$ - que objetiva tornar obrigatória a AIR por parte das Agências Reguladoras federais -,pretende-se chegar a uma possível conclusão sobre a necessidade de incorporação à AIR de outros argumentos, que não estejam restritos ao universo econômico, bem como da sua importância para a melhoria da regulação e limitação da discricionariedade do regulador.

\section{Estado Regulador}

A partir da década de 1990, iniciou-se, no Brasil, uma alteração do perfil do Estado, o qual diminuiu sua atuação direta no domínio econômico, passando a coordenar e disciplinar a prestação de serviços públicos e exploração de atividades econômicas em sentido estrito pela iniciativa privada.

A Reforma Gerencial, cujo documento básico é o Plano Diretor da Reforma do Aparelho do Estado, de setembro de 1995, objetivou desburocratizar o Estado, descentralizar a administração pública e afastar gradualmente a prestação direta dos serviços públicos por meio das desestatizações, de modo a permitir um uso mais eficiente dos recursos limitados disponíveis, bem como aperfeiçoar a qualidade da gestão.

Mencionada reforma partiu do pressuposto de que o Estado poderia ser eficiente, desde que usasse instituições e estratégias gerenciais (BRESSER-PEREIRA, 1998, p. 18), recusando, portanto, o pressuposto neoliberal de ineficiência intrínseca e generalizada do Estado. Segundo Bresser-Pereira (1998, p. 110-112), a reforma gerencial introduziu os seguintes objetivos: (i) aumentar a eficiência dos órgãos ou agências do Estado, tornando viável a efetiva utilização dos meios adequados para se atingir os fins visados (ii) melhorar a qualidade das decisões estratégias do governo e de sua burocracia, fortalecendo a capacidade do Estado de promover o desenvolvimento econômico e social, e criando condições para o investimento privado e (iii) aprimorar o caráter democrático da administração pública por envolver o controle social por parte dos cidadãos.

Para o exercício da função regulatória nesse novo padrão institucional da Administração Pública gerencial, bem como garantir a estabilidade em relação às políticas públicas estatais, previsibilidade e proteção aos investimentos dos agentes privados nos setores de infraestrutura, foram criadas autarquias em regime especial, especializadas e independentes em relação ao Executivo: as chamadas Agências Reguladoras. $^{1}$

Justen Filho (2015, p. 694) define a Agência Reguladora independente como autarquia (entidade integrante da Administração indireta, dotada de personalidade jurídica de direito público) especial, sujeita a regime jurídico que assegura a autonomia em face da Administração direta e que é investida de competência para a regulação setorial. 
Em vista dessas transformações, surge a denominação Estado regulador, como decorrência de uma reformulação da concepção teórica-política do Estado, que restringiu drasticamente sua atuação direta no domínio econômico e transformou a regulação em instrumento fundamental para atingir os fins buscados. Nas palavras de Justen Filho (2015, p. 665), "a regulação consiste na opção preferencial do Estado pela intervenção indireta, puramente normativa”. Por meio dessa solução política, entendida, em determinado contexto histórico, social e político, como a mais adequada para a obtenção dos fins buscados, o Estado reserva para si apenas o desempenho das atividades essenciais e passa a concentrar seus esforços na produção do conjunto de normas e decisões que influenciarão o funcionamento das instituições estatais e não estatais, orientando-as em direção de objetivos eleitos (JUSTEN FILHO, 2015, p. 665). Para Quadros da Silva (2014, p. 30), essa recente valorização da iniciativa privada e da concorrência como forma de melhorar a prestação de serviços públicos e a produção de bens essenciais tornou evidente a indispensabilidade da atividade regulatória para fazer frente aos novos desafios da economia de mercado.

A reforma gerencial, portanto, transformou o paradigma do Estado atuante na economia por uma intervenção regulatória, substituindo o modelo burocrático, que se preocupava com os processos, pelo modelo gerencial, voltado para a obtenção de resultados (eficiência) e qualidade da administração pública. Com isso, o debate tradicional, que estava focado na intensidade (proporcionado por ideologias opostas que confrontavam a regulação e a abstenção), cedeu lugar à discussão acerca da qualidade da regulação.

Essa modalidade de intervenção do Estado no domínio econômico está prevista no artigo 174 da Constituição e compreende as funções de (i) fiscalização, entendida como "atividade de acompanhamento, supervisão e exame das atividades econômicas exercidas pelos agentes competentes, sob o manto dos princípios e normas preestabelecidos e que permitirá a efetividade do papel normativo e regulador" (ADRI, 2010, p. 148), de (ii) incentivo, que traduz estímulo, indução das relações econômicas por meio de condições que permitam alcançar finalidades públicas que irão legitimar a efetivar a política econômica adotada, e, por fim, de (iii) planejamento, que "pressupõe uma ação estatal de provisão, de projeção, de diretriz, de fixação de metas e de busca de finalidades referentes às relações de produção, comercialização, distribuição e consumo dos bens e serviços” (ADRI, 2010, p. 148).

É oportuno salientar que a expressão "atividade econômica" foi empregada no artigo 174 em sentido amplo, ou seja, compreendendo tanto o serviço público, que está para o setor público, quanto a atividade econômica em sentido estrito, que está para o setor privado (GRAU, 2012, p. 105). É possível inferir da própria previsão do artigo, em que se estabelece que o planejamento, como uma das funções desempenhadas pelo Estado quando atua/intervém como agente normativo e regulador, é determinante para o setor público e indicativo para o setor privado.

Destaque-se, ademais, a importância do planejamento, ${ }^{2}$ que qualifica a intervenção do Estado no domínio econômico como encetada sob padrões de racionalidade sistematizada, é dizer: "decisões que vinham sendo tomadas e atos que vinham sendo praticados, anteriormente, de forma aleatória, ad hoc, passam a ser produzidos, quando objeto de planejamento, sob um novo padrão de racionalidade" (GRAU, 2012, p. 146). O reconhecimento da natureza imperativa e obrigacional do planejamento estatal pode ser de extraordinária relevância para a elaboração de uma política de desenvolvimento nacional, de implantação ininterrupta e, portanto, não afeta apenas às legislaturas (ADRI, 2010, p. 156). Não por outro motivo, diversos diplomas que dispõem sobre políticas públicas setoriais no âmbito federal impõem a obrigatoriedade do planejamento e subordinam a validade das decisões administrativas à compatibilidade com as diretrizes consagradas (JUSTEN FILHO, 2015, p. 672).

Portanto, a regulação pode ser compreendida sob dois aspectos, tal como propõe Figueiredo (2015, p. 139). No aspecto objetivo, como o conjunto de atos e medidas estatais que busca garantir a

Conforme adverte Grau (2012, p. 302), "são inconfundíveis, de um lado o planejamento da economia - centralização econômica, que importa a substituição do mercado, como mecanismo de coordenação do processo econômico, pelo plano - de outro o planejamento técnico de ação racional, cuja compatibilidade com o mercado é absoluta". 
observância dos princípios da ordem econômica no mercado, a devida e correta prestação de serviços públicos e o incentivo e fomento para implementação das políticas públicas respectivas a cada segmento da economia. No aspecto subjetivo, por sua vez, como processo estatal de normatização, fiscalização, incentivo, planejamento e mediação da atividade econômica dos particulares, com o fim de conjugar os interesses destes com os interesses públicos e coletivos, envolvidos no mercado.

\section{Por que regular?}

O constituinte adotou o regime de economia de mercado, ou capitalista, pautado na livre concorrência (art. 170, inciso IV) e na livre iniciativa (art. $1^{\circ}$, IV e 170, caput). Todavia não se trata de um sistema puro, tendo em vista que a própria Constituição estabelece metas e compromissos característicos de um Estado social. ${ }^{3}$

Parte-se do pressuposto de que o mercado, por meio da concorrência, tende a obter os melhores resultados com os menores custos, sem a necessidade de uso do poder. Entretanto, mesmo no plano econômico, "o mercado muitas vezes deixa de funcionar adequadamente em função de suas imperfeições e da existência de externalidades positivas, que não são remuneradas pelo mercado, ou negativas, que não são por ele punidas" (BRESSER-PEREIRA, 1998, p. 140).

A ordem espontânea decorrente do livre jogo dos mercados não está imune a deformações e distorções, endógenas e exógenas, razão pela qual cumpre preservá-la e defendê-la pela ação de uma ordem impositiva, que disponha de instrumentos juspolíticos preventivos e repressivos contra os abusos que a comprometam e deformem (MOREIRA NETO, 2014, p. 497).

Portanto, mediante visão estritamente econômica, essa intervenção se faz necessária para prevenir e corrigir falhas de mercado, entendidas como situações de anormalidade de efeitos danosos, potenciais ou efetivos, ao devido processo competitivo de determinado nicho da economia, que geram resultados negativos para o bem-estar socioeconômico da população (FIGUEIREDO, 2015, p. 139-140). Se a eficiência do mercado é obtida, sob uma perspectiva clássica, quando em um mercado com grande quantidade de agentes econômicos (produtores e consumidores) e informação completa e acessível a todos, os agentes racionais interagem coordenados pelo sistema de preços, objetivando a maximização de seus autointeresses, estabelecendo uma situação de equilíbrio (competição perfeita), que, por conseguinte, proporciona bem-estar para todos, as falhas se apresentarão quando esses pressupostos de funcionamento não se fizerem presentes, tornando-o inoperacional.

A primeira dessas falhas diz respeito à assimetria de informações, que ocorre quando o consumidor e/ ou o Estado não possuem conhecimento sobre como o mercado opera, ou detém informações imperfeitas, que não refletem a realidade material do respectivo setor econômico. Tal fato possibilita a prática de condutas abusivas por parte de agentes econômicos que atuam nesta conjuntura praticamente à revelia do Poder Público (FIGUEIREDO, 2015, p. 140). Daí a importância da regulação na tutela daqueles que se encontram em uma posição de hipossuficiência ante aos agentes econômicos. ${ }^{4}$

A segunda surge em uma economia de escala, quando se reduz acentuadamente o custo unitário de produção de um bem à medida que aumenta o volume produzido. Quando uma escala ótima de produção coincide com a dimensão do próprio mercado, tornando inviável a presença de outras unidades no mesmo, tem-se um monopólio natural, que nada mais é do que a possibilidade de uma empresa produzir para todo o mercado com o menor custo por unidade do que duas ou mais empresas. O monopólio natural também pode ser decorrente de situações de fato, como o acesso a uma fonte de matéria-prima rara

Conforme destaca Rocha (2010, p. 17), "a nossa constituição não é neutra quanto à ordem econômica. Ela, no entanto, não privilegiou sistemas econômicos puros, isto é, não acolheu o sistema capitalista, nem o sistema socialista, mas, antes, buscou síntese ao fundar a ordem econômica na valorização do trabalho humano e na livre iniciativa, impondo-a o fim de assegurar existência digna, conforme os ditames da justiça social".

Vide art. 411 da Lei 10.406/2002 (Código Civil), art. $4^{\circ}$ da Lei $n^{\circ} 8.078 / 1990$ (Código de Defesa do Consumidor) e art. $2^{\circ}$ da Lei $n^{\circ} 4.728 / 1965$ (Disciplina o mercado de capitais e estabelece medidas para o seu desenvolvimento). 
ou uma condição tecnológica exclusiva, como a patente de invenção (NUSDEO, 2010, p. 149). No caso do monopólio natural, o mercado pode ser aproximado da eficiência econômica por meio da regulação do preço (monopólio privado regulamentado) ou da transformação em propriedade pública (monopólio legal). ${ }^{5}$ Além disso, a deficiência da concorrência pode ser proveniente de práticas abusivas de agentes econômicos, hipótese em que se verifica um monopólio ou oligopólio convencional. Neste caso, a regulação ${ }^{6}$ se faz indispensável no estabelecimento das condutas consideradas economicamente abusivas, sendo suscetíveis, portanto, de repressão Estatal.

A terceira se refere às externalidades, que são "fatores produzidos pelos agentes que operam no mercado, na consecução de suas atividades, cujos efeitos se fazem presentes sobre terceiros não participantes do respectivo ciclo econômico" (FIGUEIREDO, 2015, p. 140). As externalidades positivas são efeitos que aumentam o bem-estar da terceira parte, enquanto as externalidades negativas são efeitos que reduzem o bem-estar (ex.: poluição). Em ambas, o custo marginal social difere do custo marginal privado, logo, os preços não refletem os custos, pelo que não se concretizam transações eficientes, o que acarreta perda de bem-estar. A intervenção do Estado na correção dessa falha se dá por meio da "internalização das externalidades", ou seja, por meio da imposição de que as externalidades componham o sistema de preços, desestimulando, assim, certas condutas prejudiciais (ex.: princípio do poluidor-pagador).

Por fim, tem-se a incapacidade de o mercado promover o acesso da coletividade aos bens essenciais. Segundo Nusdeo (2010, p. 162), trata-se de uma das mais sérias distorções da economia de mercado, "pois o fato de as necessidades por bens coletivos não serem veiculadas adequadamente pelos canais mercantis não significa que elas não existam ou não sejam importantes". Por se tratarem de bens dotados de um alto coeficiente de externalidade positiva (custo marginal social maior que o custo marginal privado), demandam a intervenção do Estado por meio do suprimento direto (art. 175, da Constituição), mediante a concessão de serviços públicos ouvia incentivo à produção, pelo setor privado. Quando o Estado transfere a prestação de serviços públicos para a esfera privada, passa a atuar de forma indireta, por meio da regulação.

Outrossim, convém notar que, historicamente, uma regulação fundamentada exclusivamente nos aspectos econômicos do mercado se mostrou insuficiente, pois a intervenção não só se faz necessária para que o mercado alcance uma eficiência econômica, mas também para proteger o consumidor, o trabalhador, o meio ambiente, a saúde da população (VALENTE, 2010, p. 91-92). Assim, em uma "segunda onda intervencionista", passou a regulação a orientar também a garantia dos direitos de minorias e promoção de valores políticos, sociais e culturais (JUSTEN FILHO, 2015, p. 690).

Finalmente, não se pode perder de vista que a intervenção do Estado na ordem econômica por meio da regulação deve observar os fundamentos e objetivos previstos nos artigos $1^{\circ}, 3^{\circ}$ e 170 da Constituição, o que demonstra claramente a preocupação do constituinte com valores outros que não somente relacionados ao funcionamento eficiente do mercado. Conforme leciona Justen Filho (2015, p. 665), a regulação compreendida como "intervenção indireta sobre a conduta dos sujeitos públicos e privados, de modo permanente e sistemático" não é um fim em si mesmo, mas um instrumento para promover conscientemente os fins políticos e os valores fundamentais buscados pelo Estado. Portanto, "toda intervenção estatal no âmbito econômico corresponde sempre à promoção de valores sociais" (JUSTEN FILHO, 2015, p. 663-664).

\footnotetext{
Note-se que nem sempre o monopólio estatal foi considerado um contrassenso econômico, mas antes uma necessidade da economia decorrente das falhas do próprio mercado. Ademais, o monopólio legal pode ser natural, decorrente de uma necessidade do próprio mercado, ou artificial, quando o Estado subtrai atividades da concorrência (TAVARES, 2011, p. 240-251). O monopólio natural não é defeso pela Constituição e não provém de práticas abusivas, conforme expresso no artigo 36, inciso II, §1 da Lei 12.529/2011. Já as hipóteses de monopólio estatal encontramse taxativamente previstas no artigo 177 da Constituição, não podendo o legislador ordinário ampliá-las.

6 Cf. art. $173, \S 4^{\circ}$, da Constituição e arts. 36 e ss. da Lei n $12.529 / 2011$.
} 


\section{Análise de Impacto Regulatório (AIR) e a melhoria da regulação}

Por se tratar de uma atividade estatal, a regulação se traduz tanto no desempenho de função administrativa como legislativa e jurisdicional. Por meio da regulação, o Estado pode exercer competências normativas primárias (como, por exemplo, o Código de Defesa do Consumidor - art. $5^{\circ}, \mathrm{XXXII}-\mathrm{e}$ a Lei de repressão ao abuso do poder econômico - art. $173, \S^{\circ}$ ) ou competências normativas de cunho administrativo, através de decretos regulamentares, resoluções, deliberações, portarias, dentre outros (BARROSO, 2005, p. 6). Tanto é assim que as primeiras formas de intervenção se manifestaram em um conjunto de atos legislativos que intentavam restabelecer a livre-concorrência, bem como criar Bancos Centrais independentes e autônomos ao governo.

A intervenção do Estado na ordem econômica por meio da regulação exercida pela competência normativa primária (art. 59 da Constituição), isto é, através do processo legislativo, está fundamentada, no Estado Democrático de Direito, nos princípios da legalidade, da igualdade e da liberdade (art. $5^{\circ}$ da Constituição), pois somente a lei pode limitar a liberdade individual, de forma geral, abstrata e impessoal. Em alguns casos, inclusive, é a própria Constituição que determina a regulação mediante lei, tal como ocorre na regulação dos investimentos de capital estrangeiro e de remessa de lucros (art. 172); na ordenação do transporte aéreo, aquático e terrestre (art. 178 e parágrafo único); na regulação da venda e revenda de combustíveis de petróleo, álcool carburante e outros combustíveis derivados de matériasprimas renováveis (art. 238).

Situação diversa é a decorrente da regulação realizada pelo poder Executivo por meio de entes da administração indireta dotados de poderes regulatórios ${ }^{7}$ (agências reguladoras, entidades de padronização, bancos centrais). Para além da discussão a respeito do déficit democrático - ínsito ao poder normativo que produz normas gerais e abstratas infralegais, mas indispensáveis diante das especificidades dos mais diversos setores, bem como da necessidade de canais de representação dos interesses envolvidos na regulação (do ente regulado e do cidadão ${ }^{8}$ ), de modo a conferir legitimidade às decisões do agente regulador -, surge a necessidade de se averiguar se a regulação se faz necessária, adequada e proporcional em sentido estrito.

Diante de uma larga utilização da regulação, discute-se a respeito da eficiência das políticas e medidas adotadas, já que uma regulação ineficiente pode acarretar dispêndio não só para o próprio Estado, mas para a sociedade em geral. Surge, pois, a necessidade de uma análise qualitativa da regulação já editada, dos processos de criação da regulação e do próprio sistema regulatório. Como assevera Freitas (2014, p. 178), as discussões sobre a regulação buscam parâmetros objetivos acerca da própria necessidade (ou desnecessidade) da intervenção regulatória e da avaliação apriorística da eficiência, dos custos e da segurança jurídica da implementação/alteração de atos regulatórios. Nasce, assim, o incentivo à utilização de procedimentos sistematizados de Análise de Impacto Regulatório (AIR), pois, apesar de importante à promoção do bem-estar econômico e social, a regulação pode apresentar custos para a sociedade, ou se tornar um obstáculo ao desenvolvimento caso se torne excessiva.

O excesso de regulação ou a inadequação das normas reguladoras à realidade econômica pode suprimir o processo competitivo e extirpar do mercado diversos agentes econômicos. Ademais, um entrave injustificável ao desenvolvimento pode ser provocado pelo surgimento das denominadas "falhas de governo", decorrentes de diversos fatores, dentre os quais se destacam: a captura de interesses do ente regulador por parte de um dos segmentos sociais regulados; a ineficiência e incapacidade técnica por parte dos agentes públicos especialistas em regulação de mercados; a dissonância entre as políticas

Não se deve confundir "regulação" com "regulamentação" que, conforme assevera Justen Filho (2015, p. 663), "corresponde ao desempenho de função normativa infraordenada, pela qual se detalham as condições de aplicação de uma norma de cunho abstrato e geral", conforme preceitua o artigo 84, incido IV, da Constituição.

8 Vide o Decreto n 8.243/2014, que Instituiu a Política Nacional de Participação Social - PNPS e o Sistema Nacional de Participação Social SNPS, e dá outras providências. 
públicas de regulação e a realidade fático-econômica do mercado; a alta carga tributária; os procedimentos administrativos excessivamente burocráticos e lentos, que tornam a autorização para exploração de determinada atividade econômica extremamente custosa; a morosidade judicial para resolução de conflitos de interesses, dentre outros (FIGUEIREDO, 2015, p. 150). No que diz respeito à excessiva burocratização (a chamada red tape), é válido destacar que, para Silva (2014, p. 31), em que pese ela seja passível de controle judicial, os próprios custos do processo e a própria fundamentação de uma ação judicial já deixam evidente que as exigências burocráticas são desarrazoadas.

Posta assim a questão, é de se dizer a Análise de Impacto Regulatório (AIR), definida pela Organização para Cooperação e Desenvolvimento Econômico (OCDE, 2008), como "ferramenta regulatória que examina e avalia os prováveis benefícios, custos e efeitos das regulações novas ou alteradas" sob uma primeira perspectiva, apresenta-se como um importante mecanismo para definição do objeto de regulação, bem como justificação da intervenção. Ademais, visa evitar problemas, como contrariedade entre normas administrativas; insegurança jurídica; dificuldades geradas em matéria de compliance; restrições à pura inovação dos agentes econômicos e sociais; riscos decorrentes de desdobramentos não previstos no conteúdo regulatório; distorções mercadológicas perpetradas por agentes econômicos interessados em prejudicar competidores por meio da regulação; favorecimento de pequenos grupos em detrimento do interesse público; captura regulatória e lobby.

Sob uma segunda perspectiva, a OCDE (2008) considera a AIR como um processo de auxílio na tomada de decisões regulatórias, incorporando-a na consulta pública, que tem como objetivo a participação dos envolvidos, bem como uma avaliação dos impactos esperados da regulamentação. Partindo dessa orientação, Freitas (2014, p. 186) conceituou a AIR como procedimento administrativo participativo que, por meio de análises consequencialistas de dados empíricos, visa conferir racionalidade aos "motivos" dos atos administrativos produzidos pelo regulador.

Cumpre-se esse procedimento em diversas fases compostas pelos seguintes instrumentos: (i) consultas públicas, por meio das quais o setor regulado se manifesta por meio de peças formais, as quais serão parte integrante do processo administrativo e sobre as quais o regulador deverá se manifestar, sob pena de violação ao devido procedimento legal; (ii) análise da redução de custos de compliance, isto é, dos custos relacionados ao atendimento das etapas burocráticas por parte das empresas, tendo em vista que um incremento elevado de custos pode ocasionar uma retração do desenvolvimento econômico do país; (iii) consideração de alternativas à regulação, isto é, da análise de modos de intervenção do Estado no domínio econômico mais eficazes à regulação, tais como adoção de políticas fomento, edição de regulações menos restritivas (soft regulation), não atuação governamental, ou até mesmo, indução à autorregulação, em atendimento ao princípio da proporcionalidade (FREITAS, 2014, p. 186-190).

Dentre os métodos de AIR, destacam-se o de custo-benefício e custo-efetividade. Por meio do primeiro, o regulador deve levar em consideração todos os custos e benefícios envolvidos, inclusive aqueles que não podem ser aferidos economicamente ${ }^{9}$ (v. g., equidade, justiça, efeitos distributivos), de modo a decidir "o que fazer". Por meio do segundo, deve comparar políticas, programas e projetos, a fim de identificar o meio mais adequado para alcançar um resultado pré-definido pelo menor custo ${ }^{10}$ isto é, deve resolver "como fazer" (FREITAS, 2014, p. 183-184). Não se deve perder de vista, entretanto, que o princípio da economicidade, previsto no art. 70 da Constituição, deve estar sempre conjugado o princípio da eficiência, previsto no art. 37, caput, do mesmo diploma.

Quanto à amplitude, a AIR pode ser global, quando relacionada à mensuração de todos os impactos macroeconômicos e multissetoriais da regulação, ou parcial, quando analisa os impactos da regulação

\footnotetext{
Salgado e Borges (2010, p. 12) advertem que "é preciso fugir do viés economicista e abranger benefícios que, em boa parte, são incertos e difusos por natureza, e custos não quantificáveis".

10 Diferentemente da ACB, a ferramenta não se aplica para determinar quais metas devem ser atingidas, mas, uma vez determinadas, é consistente em comparar quais meios são menos custosos para atingi-las (SALGADO; BORGES, 2010, p. 15)
} 
para determinado setor da economia ou da sociedade, como pequenas e médias empresas e população de menor nível de renda (FREITAS, 2014, p. 184).

Realizada uma AIR, pode-se chegar às seguintes opções: (i) não intervenção no setor em questão; (ii) medidas alinhadas com o mercado, baseadas em incentivos; (iii) disposição de informação para o setor e educação para os usuários; (iv) entendimentos voluntários como os conhecidos termos de ajustamento de conduta; (v) medidas de autorregulação e (vi) tradicional regulação de comando e controle (command and control).

A adoção da AIR tem sido recomendada pela OCDE aos seus países membros desde 1995, quando elaborou uma lista de verificação (checklist), ${ }^{11}$ que visa orientar o exercício da regulação. No Brasil, o relatório final do grupo interministerial, constituído por determinação do então presidente Luiz Inácio Lula da Silva para analisar e discutir a organização e propor medidas para o aperfeiçoamento do modelo institucional das agências reguladoras no âmbito do Poder Executivo Federal, divulgado em setembro de 2003, constatou que o desenvolvimento de instrumentos de controle social das agências era um avanço imprescindível para o bom funcionamento do modelo, fazendo-se necessário o aperfeiçoamento de mecanismos de consulta pública, ${ }^{12}$ que deveriam ser obrigatórios para todas as agências, criandose uma espécie de "semi-contencioso administrativo" (CASA CIVIL, 2003, p. 6). Mencionado relatório apontou que a legitimidade democrática poderia ser sacrificada, e que, para que isso fosse evitado, a independência em excesso das agências reguladoras, incoerente com o conceito de controle social, precisaria ser balanceada com os seguintes elementos: requerimentos de procedimento estrito, obrigação de prestar contas, sujeição à consulta pública e determinação do escopo para revisão judicial. Com essas salvaguardas, a independência das agências reguladoras poderia ser coerente com o controle social democrático (CASA CIVIL, 2003, p. 14).

Em que pese o relatório final do grupo interministerial ter recomendado a utilização de consultas públicas como procedimento padrão acerca da edição de atos normativos, com a publicação de notas explicativas e com o devido tempo hábil para a manifestação dos interessados (CASA CIVIL, 2003, p. 31), a discussão sobre a Análise de Impacto Regulatório ganhou força com a publicação, em 2007, do relatório sobre a reforma regulatória pela OCDE denominado "Brasil - Fortalecendo a Governança para o Crescimento". Na ocasião, não havia no país a obrigação de realizar uma AIR no processo de tomada de decisão, embora o tema já fizesse parte das discussões do Programa de Fortalecimento da Capacidade Institucional para Gestão em Regulação (PRO-REG).

A ANVISA foi a primeira agência selecionada pelo PRO-REG para implantação da metodologia da AIR em 2008. O Programa de Melhoria do Processo de Regulamentação (PMR) foi instituído por meio da Portaria $n^{\circ} 422 / 08$. Dentre os instrumentos adotados para o aperfeiçoamento da ação regulatória, encontrase a Agenda Regulatória Anual, a qual torna pública uma listagem de temas considerados prioritários para serem regulamentados, podendo a sociedade civil participar da escolha por meio do Conselho Consultivo e das Câmaras Setoriais, e também a Análise de Impacto Regulatório, que teve como projetopiloto a revisão da Resolução da Diretoria Colegiada (RDC) n.॰33/2006, a qual trata do Regulamento Técnico para o funcionamento dos Bancos de Células e Tecidos Germinativos (BCTG). O processo de AIR, ainda que parcial, culminou na emissão, em junho de 2010, do Relatório Preliminar de Análise de Impacto Regulatório e na Consulta Pública n88, em 11 de agosto de 2010 (LIMA, 2010, p. 120-123). Além disso, o Regimento Interno da ANVISA, aprovado pela Resolução 29/2015, ao definir a estrutura organizacional e as respectivas competências, estabelece que compete à Agência-Geral de Análise de

11 "O regulador deve responder os seguintes questionamentos: 1. O problema está definido claramente? 2. 1) O problema está definido claramente? A ação governamental é justificada? 3. A regulação é a melhor forma de ação governamental? 4. Existe base legal para a regulação? 5. Qual o nível apropriado de governo para esta ação? 6. Os benefícios da regulação justificam os custos? 7. A distribuição dos efeitos na sociedade é transparente? 8. A regulação é clara, consistente, compreensível e acessível aos usuários? 9. Todas as partes interessadas tiveram a oportunidade de apresentar suas sugestões/considerações? 10. Como a aplicação e cumprimento da regulação serão obtidos?” (OCDE, 2008).

12 No que diz respeito aos mecanismos de controle social, em especial, à consulta pública, o relatório constatou que, na maioria dos casos, as agências respondiam às consultas sem a devida fundamentação ou simplesmente não respondiam os questionamentos (CASA CIVIL, 2003, p. 26). 
Impacto Regulatório e Acompanhamento de Mercados, por meio da Coordenação de Análise de Impacto Regulatório e Assessoramento Econômico em Regulação, promover análises de impacto regulatório, estudos econômicos e acompanhamento de mercados (art. 4º,$\S 10$, II, 'a' e 'b' c/c art. 151 e 152).

A Análise de Impacto Regulatório também está prevista na Norma de Organização $n^{\circ} 40$, aprovada pela Resolução Normativa $n^{\circ}$ 540, de março de 2013, da Agência Nacional de Energia Elétrica (ANEEL). Contudo, a obrigatoriedade da AIR previamente à expedição de qualquer ato normativo, conforme estabelecido no artigo $1^{\circ}$ da mencionada norma, não se justifica levando em consideração a análise custobenefício, já que determinadas propostas regulatórias (como as que objetivam disciplinar o funcionamento interno da agência) não afetam os interesses dos regulados ao ponto de legitimar os custos inerentes à realização de uma AIR (FREITAS, 2014, p. 193-194). O Regimento Interno da Agência Nacional de Telecomunicações (ANATEL), aprovado pela Resolução 612, de 29 de abril de 2013, em que pese estabeleça no artigo 62, parágrafo único, que os atos de caráter normativo a que se refere o caput deverão ser precedidos de AIR, comporta exceções em situações expressamente justificadas.

A Resolução de Diretoria Colegiada n 52/13 da Agência Nacional do Cinema (ANCINE), por sua vez, traz expressamente, em seu artigo $3^{\circ}$, os casos em que será realizada a AIR, sendo que é de competência de cada superintendência a realização das análises de impacto relativas às suas respectivas matérias (art. 28, XIV c/c art. $4^{\circ}$, IX do Regimento Interno aprovado pela Resolução $n^{\circ}$ 59, de 02 de abril de 2014).

AAgência Nacional de Aviação Civil (ANAC), por meio da Instrução Normativa $n^{\circ}$ 61/2012, estabeleceu requisitos mínimos a serem observados para a realização de análise preliminar das proposições de atos normativos e decisórios, competindo à Superintendência de Planejamento Institucional (SPI) a elaboração e a atualização de formulário específico que deverá ser preenchido pelas unidades organizacionais quando da proposição de resoluções e de concessão de isenções de cumprimento de requisitos técnicos.

No que diz respeito à Agência Nacional do Petróleo, Gás Natural e Biocombustíveis (ANP), embora não haja previsão da AIR em seu Regimento Interno, aprovado pela Portaria $n^{\circ} 69$, de 6 de abril de 2011, recentemente foi instituído um grupo de trabalho com o propósito de realizar Análise de Impacto Regulatório (AIR) sobre o tema "Requalificação de Recipientes Transportáveis de Aço para Gás Liquefeito de Petróleo (GLP)", por meio da Portaria $n^{\circ} 255$, de 22 de novembro de 2013, cujo relatório se encontra disponível no sítio eletrônico da ANP, junto ao Aviso de Consulta Pública n 10/2015, publicado no Diário Oficial da União em 18 de maio de 2015.

Por sua vez, os Regimentos Internos da Agência Nacional de Saúde Suplementar (ANS), da Agência Nacional de Transportes Aquaviários (ANTAQ), Agência Nacional de Transportes Terrestres (ANTT), aprovados pelas Resoluções de $n^{\circ} 197 / 2009$, n 3.585/2014 e $n^{\circ} 3.000 / 2009$, nesta ordem, tão somente mencionam a Análise de Impacto Regulatório ao definir as competências, nos artigos $7^{\circ}, \mathrm{XXI}, 7^{\circ}-\mathrm{A}, \mathrm{XI}$, alínea a e 14-A, VII; art. 52, I e IV; art. 54, VIII, respectivamente. Por fim, com relação à Agência Nacional de Águas (ANA), ainda não há previsão.

Portanto, o que se extrai das mencionadas disposições é que a AIR já é um procedimento difundido nas agências reguladoras brasileiras, consoante recomendação da OCDE. Todavia, o que falta é uniformidade e simetria na adoção e condução do procedimento.

Tentando estabelecer a obrigatoriedade de implantação da AIR por todas as agências reguladoras, bem como transformá-la em um procedimento de atos ordenados e uniformes, tal como recomendado pela OCDE, ${ }^{13}$ recentemente foi apresentado um Projeto de Lei ${ }^{0} 1.539 / 2015$ pelo deputado Eros Biondini, no qual a AIR é definida, ${ }^{14}$ resumidamente, como um procedimento administrativo que, baseado no uso

13 "AAIR precisa ser apoiada por um instrumento legislativo que a torne compulsória para órgãos e entidades integrantes da administração pública" (OCDE, 2007, p. 63).

14 "Procedimento administrativo de observância obrigatória, voltado a subsidiar e orientar a tomada de decisões regulatórias pelas Agências reguladoras, bem como permitir o monitoramento de sua implementação, baseado no uso sistemático de análise econômica de custos, benefícios e dos possíveis efeitos de uma decisão regulatória, tendo em consideração os objetivos a serem perseguidos em cada setor regulado". 
sistemático de análise econômica de custos, benefícios e possíveis efeitos de uma decisão regulatória, tem por objetivo subsidiar e orientar a tomada de decisões regulatórias das agências reguladoras.

O projeto obriga as agências reguladoras no âmbito da administração federal, sem prejuízo de outras agências reguladoras definidas por lei ou por decreto, a realizarem a Análise de Impacto Regulatório (AIR) em todos os atos normativos, planos setoriais e edição, alteração e prorrogação de outorgas, excepcionando apenas as hipóteses de atos administrativos concretos, voltados a disciplinar situação específica e com destinatários individualizados, tais como expedição de autorizações e licenças, bem como os atos normativos de simples organização interna que não criam direitos ou deveres a terceiros, nem causam impactos orçamentários aos demais órgãos ou entidades da Administração.

A AIR, segundo o projeto, tem por objetivo: orientar e subsidiar o processo de tomada de decisão pelas agências; medir as potenciais consequências de uma iniciativa regulatória; propiciar maior eficiência e eficácia das decisões regulatórias, maior coerência e qualidade da política regulatória e maior transparência para as decisões regulatórias; permitir o monitoramento e controle do processo de tomada de decisões regulatórias pelos agentes regulados e pela sociedade civil; e, por fim, propiciar o acompanhamento e aprimoramento do resultado das políticas regulatórias em curto, médio e longo prazo.

Ademais, o projeto detalha minuciosamente todas as etapas que precisarão ser seguidas pelas agências, sob pena de nulidade da regulação, quais sejam: definição do problema e dos objetivos a serem perseguidos; chamamento público para oferecimento de oferta de alternativas para atingimento dos objetivos; seleção das alternativas e levantamento de dados correlatos; consulta pública; análise circunstanciada das alternativas e das contribuições obtidas em consulta pública e validação dos dados por parte da agência reguladora; emissão do relatório de AIR; escrutínio e parecer de validação por parte da Secretaria de Acompanhamento Econômico - SEAE do Ministério da Fazenda; e, monitoramento da alternativa adotada, a ser realizado conjuntamente pela agência reguladora e pela SEAE.

O primeiro aspecto relevante do Projeto diz respeito à participação pública, que ocorrerá em três momentos: (i) após a definição do problema e dos objetivos, através do chamamento público, para que os interessados ofereçam contribuições alternativas para atingir os objetivos perseguidos, que não vinculam a decisão do regulador, mas devem ser consideradas no processo de análise e levantamento; (ii) após a conclusão da etapa de seleção de alternativas, por meio da primeira consulta pública; e, (iii) após a elaboração do relatório da AIR, na segunda consulta pública. O chamamento e as consultas públicas deverão ser formalizados por publicação no Diário Oficial da União, com prazo não inferior a 15 (quinze) dias, divulgados por meio das páginas das agências na Internet e comunicadas: aos órgãos de defesa da concorrência, do meio ambiente e do consumidor; às instituições de representação dos agentes econômicos que atuem no setor; às instituições de representação dos usuários e consumidores da atividade ou serviço objeto da AIR, e à SEAE. Ademais, caberá ao grupo de trabalho condutor da AIR responder individual, justificada e circunstancialmente às contribuições recebidas.

O segundo aspecto importante do projeto diz respeito à submissão do relatório da AIR à Secretaria de Acompanhamento Econômico - SEAE, que poderá ratificá-lo com ou sem ressalvas ou rejeitálo, solicitando a retomada da análise a partir dos pontos que entender comprometidos, na esteira da competência genérica que já Ihe é conferida pela Lei $n^{\circ} 12.529 / 11$, artigo 19. Além do poder de escrutínio e validação sobre os estudos da AIR, o projeto de lei confere à SEAE o poder de acompanhamento a posteriori das medidas adotadas.

Por fim, estabelece que as deliberações dos órgãos superiores das agências deverão ser orientadas pelo relatório da AIR, e que quaisquer decisões contrárias serão devidamente motivadas. A expressa previsão da necessidade de motivação, sem dúvida, é um dos seus principais aspectos.

Embora o projeto estabeleça a adoção da AIR pelas agências reguladoras, é de se verificar que ela deve alcançar todas as instâncias governamentais como competências governamentais regulatórias (ARAGÃO, 2012). Isso porque na regulação do setor de energia, por exemplo, seria fundamental uma AIR não somente das decisões da ANEEL e da ANP, mas também do Conselho Nacional de Política Energética 
(CNPE), do Ministério de Minas e Energia (MME) e de outros órgãos que eventualmente tenham conexão com a regulação dessa matéria. Trata-se, aliás, de uma das recomendações feitas pela OCDE (2007, p. 339-342). Além disso, destaque-se a necessidade de Análise de Impacto Regulatório sob a perspectiva do consumidor, tal como expressamente determinado pelo artigo $6^{\circ}$, inciso I, do Decreto $7963 / 13$, que institui o Plano Nacional de Consumo e Cidadania e cria a Câmara Nacional das Relações de Consumo.

Denota-se, por todo o exposto, que a adoção da AIR, tanto em novas propostas regulatórias quanto na revisão da regulação já existente, não pode ser vista como mais uma exigência burocrática, uma etapa custosa (SALGADO; BORGES, 2010, p. 9), mas antes como uma exigência dos princípios da motivação, eficiência, proporcionalidade e da boa-administração, pois impõe à Administração Pública que demonstre os motivos pelos quais adotou determinada medida regulatória, bem como que tal medida é adequada, necessária e proporcional em sentido estrito. Por outro lado, garante participação, transparência e previsibilidade aos cidadãos e empresas, o que confere legitimação às decisões do agente regulador e reduz o déficit democrático da regulação feita por meio de órgãos autônomos não eleitos (VALENTE, 2010, p. 20).

Para isso, a AIR deve ser feita a priori, pois, caso contrário, isto é, caso promovida em um momento já avançado do processo decisório, "reduz-se para justificar a decisão já tomada, sendo melhor não fazêla, dado o dispêndio de recursos públicos envolvidos" (SALGADO; BORGES, 2010, p. 9). Isso não exclui, entretanto, a necessidade de revisão das regulações, a qual deve ser precedida, sempre que possível, de novas AIRs (OCDE, 2007, p. 67-68), para que continuem a cumprir com os objetivos pretendidos de modo eficiente e eficaz diante das mudanças sociais, econômicas ou tecnológicas.

\section{Restrição da discricionariedade}

Analisadas a importância, a necessidade e a possível obrigatoriedade de adoção da AIR por parte dos agentes reguladores, cumpre verificar se ela representaria uma limitação da discricionariedade investida às agências reguladoras, na medida em que procedimentaliza e racionaliza as decisões regulatórias.

Segundo Albuquerque (2006, p. 25), "por si só, a AIR não é capaz de determinar as decisões regulatórias, mas consegue informar as discussões e o processo decisório com dados concretos que clareiam o leque de opções disponíveis". Para Freitas (201, p. 186), na medida em que a AIR é um procedimento administrativo participativo, isto é, uma sucessão encadeada de atos - audiências públicas, consultas públicas e análises técnicas - que necessitam da participação do setor regulado afetado pela proposta regulatória, de modo a conferir substratos fáticos e jurídicos para a edição do ato regulatório, uma vez realizado, vinculará o regulador aos motivos nele apresentados ("teoria dos motivos determinantes"), de modo que posterior alteração maculará o ato administrativo por vício de legalidade, nos termos do artigo $2^{\circ}$, parágrafo único, alínea d, da Lei n 4.717/1965 (Lei de Ação Popular).

Justen Filho (2015, p. 669) destaca que, muito embora a competência regulatória compreenda atividades de cunho vinculado e adoção de escolhas discricionárias, isso não significa que o Estado possua autonomia para produzir uma regulação desvinculada da realidade fática ou do conhecimento técnico. Logo, a validade da regulação depende da "observância de um procedimento adequado a identificar os problemas, a avaliar as consequências das soluções cabíveis, a permitir a ampla discussão das propostas e a demonstrar que a escolha adotada é a mais satisfatória" (JUSTEN FILHO, 2015, p. 569-570).

Muito embora a AIR seja um instrumento apto a melhorar a qualidade regulatória, é importante destacar que a atividade estatal está sujeita a falhas e excessos, motivo pelo qual, para Silva (2014, p. 35), "nem mesmo a atual tendência de instituir mecanismos de participação do 'público' no processo de decisão das agências, como corolário da adoção de um controle social, tornaria menos importante o controle judicial". Para referido autor, os atos administrativos devem ser controlados por diversas formas, instrumentos e instâncias, em especial pelo poder Judiciário, em observância à universalização da jurisdição, princípio ligado ao acesso à justiça (SILVA, 2014, p. 32-33). É por meio do controle judicial 
que os interessados afetados pela má atuação dos órgãos reguladores podem obter a anulação dos atos lesivos, "assegurando a proteção de seus direitos, mas sem retirar dos órgãos reguladores a atribuição originária e privativa de atuar decisivamente nos setores regulados" (SILVA, 2014, p. 294).

Portanto, com a AIR, a discricionariedade regulatória passa a ser vista como competência administrativa (não mera faculdade) de avaliar e escolher, no plano concreto, soluções embasadas em razões robustas (fáticas e jurídicas), as quais devem atender com estimativas seguras os requisitos formais e substanciais do direito fundamental à boa administração, que "vincula racionalmente o gestor público e o força a medir consequências sistêmicas de suas opções, pois terá de justificá-las coerentemente, sobretudo em seu custo-efetividade" (FREITAS, 2015, p. 118). Logo, cumpre ao regulador expor as razões fáticas e jurídicas que sustentam a adoção, ou não, das possíveis medidas apontadas (não intervenção no setor em questão, medidas alinhadas com o mercado, baseadas em incentivos, disposição de informação para o setor e educação para os usuários, regulação de comando e controle, dentre outros) e o porquê. Assim, "uma vez enunciados pelo agente os motivos em que se calçou, ainda quando a lei não haja expressamente imposto a obrigação de enunciá-los, o ato só será válido de estes realmente ocorrerem e o justificarem" (MELLO, 2011, p. 408), segundo a teoria dos motivos determinantes. Dessa forma, além de diminuir a discricionariedade do regulador, a AIR, como processo que visa e racionalizar as decisões regulatórias, torna possível o posterior controle dos atos administrativos pelo Poder Judiciário.

\section{Conclusão}

O Estado, como agente regulador da ordem econômica, toma decisões cujos custos e benefícios serão, direta ou indiretamente, suportados pelos cidadãos. Assim sendo, essa modalidade de intervenção no domínio econômico deve estar fundamentada em padrões de racionalidade sistematizada, conforme estabelece o artigo 174 da Constituição quando atribui ao Estado regulador a função de planejamento. Daí a necessidade de se adotar práticas de avaliação ex ante sobre os impactos econômicos, sociais e ambientais de determinada regulação, assim como análises ex post, a fim de verificar se a regulação continua a cumprir com seus objetivos de forma eficiente e eficaz.

A Análise de Impacto Regulatório (AIR) não é apenas uma ferramenta apta a avaliar os custos, benefícios e efeitos da regulação, mas, como procedimento administrativo voltado à análise das medidas regulatórias a serem adotadas ou já adotadas pelos reguladores com base em evidências empíricas, resulta na introdução de mecanismos de legitimação democrática e de responsabilização do regulador, visto que possibilita a participação dos envolvidos no processo regulatório, limita a discricionariedade do regulador e viabiliza o posterior controle da decisão regulatória pelo Poder Judiciário.

\section{Referências}

ADRI, Renata Porto. Da função estatal de planejar a atividade econômica: breves reflexões sobre o art. 174 da Constituição da República de 1988. In: SPARAPANI, Priscilia; ADRI, Renata Porto (Coord.). Intervenção do Estado no domínio econômico e no domínio social: homenagem ao professor Celso Antônio Bandeira de Mello. Belo Horizonte: Fórum, 2010. p. 145-158.

ALBUQUERQUE, Kélvia Frota de. A retomada da reforma/melhora regulatória no Brasil: um passo fundamental para o crescimento econômico sustentado. Brasília: SEAE/MF, 2013. (Documento de Trabalho, $n^{\circ}$ 35). Disponível em: <http://www.seae.fazenda.gov.br/central-de-documentos/documentosde-trabalho/documentos-de-trabalho-2006/DT_35.pdf>. Acesso em: 12 dez. 2015.

\section{AGÊNCIA NACIONAL DO PETRÓLEO, GÁS NATURAL E BIOCOMBUSTÍVEIS - ANP. Relatório de}

Análise de Impacto Regulatório: requalificação de recipientes transportáveis de aço para gás liquefeito de petróleo (GLP). Brasília, 2015. Disponível em: <http://www.anp.gov.br/?dw=74931>. Acesso em: 20 jan. 2016. 
AGÊNCIA NACIONAL DE VIGILÂNCIA SANITÁRIA - ANVISA. Relatório Preliminar de Análise de Impacto Regulatório. Brasília, 2010. Disponível em: <http://portal.anvisa.gov.br/wps/wcm/connect/25d6 08804f7338d4a41ff59a71dcc661/14-07-exemplo-de-air-da-anvisa.pdf?MOD=AJPERES>. Acesso em: 20 jan. 2016.

BARROSO, Luis Roberto. Constituição, ordem econômica e agências reguladoras. Revista Eletrônica de Direito Administrativo Econômico, Salvador, n. 1, fev./mar./abr. 2005. Disponível em: <http://www. direitodoestado.com.br>. Acesso em: 12 dez. 2015.

BRASIL. Congresso Nacional. Projeto de Lei $n^{\circ}$ 1.539/2015. Disponível em: <http://www2.camara.leg. br/proposicoesWeb/prop_mostrarintegra;jsessionid=0E6A4D328962E24E5E9213B11A5CBC21. proposic oesWeb2?codteor=1334093\&filename=PL+1539/2015>. Acesso em: 20 jan. 2016.

BRASIL. Constituição da República Federativa do Brasil, de 05 de outubro de 1988. Diário Oficial da União, Brasília, 1988. Disponível em: <http://www.planalto.gov.br/ccivil_03/Constituicao/Constituicao. htm>. Acesso em: 20 jan. 2016.

BRASIL. Decreto n 8.243, de 23 de maio de 2014. Diário Oficial da União, Brasília, 2014. Disponível em: <http://www.planalto.gov.br/ccivil_03/_Ato2011-2014/2014/Decreto/D8243.htm>. Acesso em: 20 jan. 2016.

BRASIL. Instrução Normativa $n^{\circ}$ 61, de 03 de julho de 2012. Boletim de Pessoal e Serviço, Brasília, v. 7, n. 26, S2 (Edição Suplementar), 2012. Disponível em: <http://www2.anac.gov.br/biblioteca//N/2012/ IN2012-0061.pdf>. Acesso em: 20 jan. 2016.

BRASIL. Lei no 4.728, de 14 de julho de 1965. Diário Oficial da União, Brasília, 1965. Disponível em: <http://www.planalto.gov.br/ccivil_03/LEIS/L4728.htm>. Acesso em: 20 jan. 2016.

BRASIL. Lei n 8.078, de 11 de setembro de 1990. Código de Defesa do Consumidor. Diário Oficial da União, Brasília, 1990. Disponível em: < http://www.planalto.gov.br/ccivil_03/Leis/L8078.htm>. Acesso em: 20 jan. 2016.

BRASIL. Lei n 10.406, de 10 de janeiro de 2002. Código Civil. Diário Oficial da União, Brasília, 2002. Disponível em: <http://www.planalto.gov.br/ccivil_03/leis/2002/L10406.htm>. Acesso em: 20 jan. 2016.

BRASIL. Portaria $n^{\circ}$ 69, de 06 de abril de 2011. Diário Oficial da União, Brasília, 2011. Disponível em: <http://nxt.anp.gov.br/NXT/gateway.dll?f=templates\&fn=default.htm\&vid=anp:10.1048/enu>. Acesso em: 20 jan. 2016.

BRASIL. Portaria n 255, de 22 de novembro de 2013. Diário Oficial da União, Brasília, 2013. Disponível em: <http://nxt.anp.gov.br/NXT/gateway.dll?f=templates\&fn=default.htm\&vid=anp:10.1048/ enu>. Acesso em: 20 jan. 2016.

BRASIL. Portaria $n^{\circ}$ 422, de 15 de abril de 2008. Diário Oficial da União, Brasília, 2008. Disponível em: < http://www.anvisa.gov.br/divulga/noticias/2008/170408_1.pdf >. Acesso em: 20 jan. 2016.

BRASIL. Resolução da Diretoria Colegiada n॰29/2006, de 21 de julho de 2015. Diário Oficial da União, Brasília, 2015. Disponível em: <http://portal.anvisa.gov.br/wps/wcm/ connect/fef335804936aec7a64ebf7e28bd3bd1/RDC+29+de+21+julho+de+2015++Regimento+Interno+da+Anvisa.pdf?MOD=AJPERES>. Acesso em: 20 jan. 2016.

BRASIL. Resolução da Diretoria Colegiada n. 33/2006, de 8 de julho de 2011. Diário Oficial da União, Brasília, 2011. Disponível em: <http://portal.anvisa.gov.br/wps/wcm/connect/ e277480049b2900299e4bf6dcbd9c63c/RESOLU\%C3\%87\%C3\%83O+33.pdf?MOD=AJPERES>. Acesso em: 20 jan. 2016.

BRASIL. Resolução da Diretoria Colegiada $n^{\circ}$ 52, de 10 de janeiro de 2013. Diário Oficial da União, Brasília, 2013. Disponível em: <http://www.ancine.gov.br/sites/default/files/resolucoes-diretoria-colegiada/ RDC\%2052\%20alterada\%20pela\%20RDC\%2061_0.pdf>. Acesso em: 20 jan. 2016.

BRASIL. Resolução n 59, de 02 de abril de 2014. Diário Oficial da União, Brasília, 2014. Disponível em: <http://www.ancine.gov.br/sites/default/files/resolucoes-diretoria-colegiada/RDC $\% 2059 \% 20$ e 20 ANEXO.pdf>. Acesso em: 20 jan. 2016. 
BRASIL. Resolução $n^{\circ}$ 612, de 29 de abril de 2013. Diário Oficial da União, Brasília, 2013. Disponível em: <http://www.anatel.gov.br/legislacao/resolucoes/2013/450-resolucao-612>. Acesso em: 20 jan. 2016.

BRASIL. Resolução $n^{\circ}$ 3000, de 28 de janeiro de 2009. Diário Oficial da União, Brasília, 2009.

Disponível em: < http://www.antt.gov.br/index.php/content/view/4000/Resolucao_n_3000.html>. Acesso em: 20 jan. 2016.

BRASIL. Resolução n 3.585, de 18 de agosto de 2014. Diário Oficial da União, Brasília, 2014.

Disponível em: <http://www.antaq.gov.br/portal/pdfSistema/Publicacao/0000006716.pdf>. Acesso em: 20 jan. 2016.

BRASIL. Resolução Normativa n 197, de 16 de julho de 2009. Diário Oficial da União, Brasília, 2009. Disponível em: < http://www.ans.gov.br/index2.php?option=com_legislacao\&view=legislacao\&task=Texto Lei\&format=raw\&id=MTY2NQ==>. Acesso em: 20 jan. 2016.

BRASIL. Resolução Normativa n 540, de 12 de março de 2013. Diário Oficial da União, Brasília, 2013. Disponível em: <http://www.aneel.gov.br/cedoc/ren2013540.pdf>. Acesso em: 20 jan. 2016.

BRESSER-PEREIRA, Luiz Carlos. Reforma do Estado para a cidadania: a reforma gerencial brasileira na perspectiva internacional. São Paulo: Centro Regional de Ayuda Técnica, 1998.

CASA CIVIL. Relatório final do grupo de trabalho interministerial: Análise e avaliação do papel das agências reguladoras no atual arranjo institucional brasileiro. Brasília, 2003. Disponível em: <http://www. bresserpereira.org.br/Documents/MARE/Agencias/avaliacao_das_agencias_reguladoras_-_casa_civil. pdf>. Acesso em: 12 dez. 2015.

FIGUEIREDO, Leonardo Vizeu. Lições de direito econômico. 8. ed. rev. e atual. Rio de Janeiro: Forense, 2015.

FREITAS, Juarez. Políticas públicas, avaliação de impactos e o direito fundamental à boa administração. Seqüência: Estudos Jurídicos e Políticos, Florianópolis, v. 36, n. 70, p. 115-133, jun. 2015. Disponível em: <https://periodicos.ufsc.br/index.php/sequencia/article/view/2177-7055.2015v36n70p115>. Acesso em: 12 dez. 2015.

FREITAS, Rafael Véras de. A Análise de Impacto Regulatório (AIR) no setor de energia elétrica. Revista brasileira de direito público, Salvador, v. 12, n. 46, p. 177-200, jul./set. 2014.

GRAU, Eros Roberto. A ordem econômica na constituição de 1988: (interpretação e crítica). 15. ed. São Paulo: Malheiros, 2012.

JUSTEN FILHO, Marçal. Curso de direito administrativo. 11. ed. rev. atual. e ampl. São Paulo: Revista dos Tribunais, 2015.

LIMA, Valéria Athayde Fontelles de. A avaliação de impacto regulatório no contexto brasileiro.

Rio de Janeiro, 2010. Dissertação (Mestrado em Políticas Públicas, Estratégias e Desenvolvimento) Instituto de Economia, Universidade do Rio de Janeiro, 2010.

MELLO, Celso Antônio Bandeira de. Curso de direito administrativo. 29. ed. São Paulo: Malheiros, 2011.

MOREIRA NETO, Diogo de Figueiredo. Curso de direito administrativo. 16. ed. Rio de Janeiro: Forense, 2014.

NUSDEO, Fábio. Curso de economia: introdução ao direito econômico. 6. ed. rev. e atual. São Paulo: Revista dos Tribunais, 2010.

ORGANIZAÇÃO PARA A COOPERAÇÃO E DESENVOLVIMENTO ECONÓMICO - OCDE. Building an institutional framework for regulatory impact analysis. Version 1.1 Regulatory Policy Division Directorate for Public Governance and Territorial Development. Paris, 2008. Disponível em: <http://www. oecd.org/gov/regulatory-policy/40984990.pdf> Acesso em: 12 dez. 2015.

ORGANIZAÇÃO PARA A COOPERAÇÃO E DESENVOLVIMENTO ECONÓMICO - Relatório sobre a Reforma Regulatória. BRASIL - Fortalecendo a governança para o crescimento. 2007. Disponível em: <portal2.tcu.gov.br/portal/pls/portal/docs/2064390.PDF >. Acesso em: 12 dez. 2015. 
ORGANIZAÇÃO PARA A COOPERAÇÃO E DESENVOLVIMENTO ECONÓMICO. The OECD Report on Regulatory Reform. Paris, 1997.

ROCHA, Silvio Luís Ferreira da. Breves considerações sobre a intervenção do Estado no domínio econômico e a distinção entre atividade econômica e serviço público. In: SPARAPANI, Priscilia; ADRI, Renata Porto (Coord.). Intervenção do Estado no domínio econômico e no domínio social: homenagem ao professor Celso Antônio Bandeira de Mello. Belo Horizonte: Fórum, 2010. p. 13-27.

SALGADO, Lucia Helena; BORGES, Eduardo Bizzo de Pinho. Análise de impacto regulatório: uma abordagem exploratória. Brasília: IPEA, 2010. (Texto para Discussão, n 1463). Disponível em: <http:// www.ipea.gov.br/portal/images/stories/PDFs/TDs/td_1463.pdf>. Acesso em: 12 dez. 2015.

SILVA, Fernando Quadros da. Controle judicial das agências reguladoras: aspectos doutrinários e jurisprudenciais. Porto Alegre: Verbo Jurídico, 2014.

TAVARES, André Ramos. Direito constitucional econômico. 3. ed. rev. e atual. São Paulo: Método, 2011.

VALENTE, Patrícia Rodrigues Pessôa. Avaliação de impacto regulatório: uma ferramenta à disposição do Estado. 2010. Dissertação (Mestrado em Direito do Estado) - Faculdade de Direito, Universidade de São Paulo, São Paulo, 2010. Disponível em: <http://www.teses.usp.br/teses/disponiveis/2/2134/tde26032012-092844/>. Acesso em: 12 dez. 2015.

Recebido em: 21/01/2016

Aprovado em: 25/08/2016 